OPEN ACCESS

Edited by:

Cheorl-Ho Kim

Sungkyunkwan University,

South Korea

Reviewed by:

Ajay Bommareddy,

Wilkes University, United States William Chi-Shing Tai,

The Hong Kong Polytechnic

University, Hong Kong

*Correspondence:

Michael E. Cox

mcox@prostatecentre.com

Manju Sharma

msharma@prostatecentre.com

Specialty section:

This article was submitted to

Ethnopharmacology,

a section of the journal

Frontiers in Pharmacology

Received: 04 November 2017

Accepted: 22 February 2018

Published: 09 March 2018

Citation:

Sharma M, Levenson $C$

Browning JC, Becker EM,

Clements I, Castella $P$ and Cox ME

(2018) East Indian Sandalwood Oil Is

a Phosphodiesterase Inhibitor: A New

Therapeutic Option in the Treatment

of Inflammatory Skin Disease.

Front. Pharmacol. 9:200.

doi: 10.3389/fphar.2018.00200

\section{East Indian Sandalwood Oil Is a Phosphodiesterase Inhibitor: A New Therapeutic Option in the Treatment of Inflammatory Skin Disease}

\author{
Manju Sharma ${ }^{1 *}$, Corey Levenson ${ }^{2}$, John C. Browning ${ }^{3}$, Emily M. Becker ${ }^{3}$, \\ lan Clements ${ }^{2}$, Paul Castella ${ }^{2}$ and Michael E. Cox ${ }^{1,4 *}$ \\ ${ }^{1}$ The Vancouver Prostate Centre, Vancouver Coastal Health Research Institute, Vancouver, BC, Canada, ${ }^{2}$ Santalis \\ Pharmaceuticals, Inc., San Antonio, TX, United States, ${ }^{3}$ Texas Dermatology and Laser Specialists, San Antonio, TX, \\ United States, ${ }^{4}$ Department of Urologic Sciences, The University of British Columbia, Vancouver, BC, Canada
}

Cyclic adenosine monophosphate phosphodiesterases (PDEs) regulate proinflammatory cytokine production. One isoform, PDE4, is overactive in chronic relapsing inflammatory skin diseases: psoriasis and eczema/atopic dermatitis, and in several cancers. East Indian sandalwood oil (EISO) has significant anti-inflammatory properties. Here, we report that $75 \%$ of pediatric eczema/atopic dermatitis patients treated with topical EISO formulations achieved a $>50 \%$ reduction in their Eczema Area and Severity Index score. EISO treatment of a psoriasis model reduced PDE4 expression and reversed histopathology. EISO directly inhibited PDE enzymatic activity in vitro. In lipopolysaccharide-stimulated human dermal fibroblast, BEAS-2B, A549, and THP-1 cells, EISO suppressed total cellular PDE activity, PDE4, and 7 transcript levels, nuclear factor kappa B (NF-кB) activation, and pro-inflammatory cytokines/chemokine production. These results suggest that EISO anti-inflammatory activity is mediated through suppressing PDE activity, thus facilitating CAMP-regulated inhibition of NF-кB and indicate EISO as an attractive natural therapeutic for chronic and acute inflammatory disorders.

Keywords: psoriasis, atopic dermatitis, eczema, cancer, phosphodiesterase, skin organoid, anti-inflammatory, anti-proliferative

\section{INTRODUCTION}

Psoriasis (PS) and atopic dermatitis (AD) are chronic or recurrent inflammatory dermatologic disorders that significantly impact quality of life for millions of patients and tax health care resources worldwide (Carroll et al., 2005; Mancini et al., 2008; Arkwright et al., 2013; Parisi et al., 2013). PS and AD are clearly separable disorders with AD typically presenting in early childhood and PS typically presenting in late adolescence and early adulthood (Guttman-Yassky et al., 2011; Czarnowicki et al., 2014; Noda et al., 2015; Chiricozzi et al., 2016). However, numerous environmental and genetic factors contribute to these cytokine-mediated chronic skin conditions, and it is difficult to differentiate PS and AD during the acute erythrodermic phase since both are caused by aberrant production of inflammatory cytokines/chemokines by keratinocytes and innate and adaptive immune cell populations (Schafer, 2012). Not surprisingly, therapies that target inflammatory cytokines/chemokines signaling pathways provide symptomatic benefit to PS and AD patients (Gittler et al., 2012; Lowes et al., 2014). 
Existing topical and systemic medications for these disorders are not universally effective and pose adverse side effect risks requiring intermittent use and close monitoring ( $\mathrm{Hsu}$ and Armstrong, 2014). Identification of topical anti-inflammatory agents that can abrogate symptoms would be useful for the treatment of chronic inflammatory skin disorders. Natural products remain the best source for the development of new therapies because of their structural diversity and they do not match any source of small molecules (Newman and Cragg, 2012). While widely used in aromatherapy, the essential oil from Indian sandalwood trees, Santalum album (Santalaceae), commonly known as East Indian sandalwood oil (EISO), is a potent antiinflammatory, antiseptic and astringent agent (Burdock and Carabin, 2008; Sharma et al., 2014; Bommareddy et al., 2017), properties ideal for treatment of inflammatory skin disorders as has been reported for psoriasis (Sharma et al., 2017) and acne (Moy et al., 2012).

Cyclic adenosine monophosphate (cAMP) is an important regulator of immune and inflammatory responses, and turnover of intracellular cyclic nucleotides is dependent on the activity of phosphodiesterases (PDEs) (Oldenburger et al., 2012). PDE isoenzymes levels are regulated by various stimuli including prostaglandin E2-induced expression of PDE3B, 4A4, 4A1, $4 \mathrm{D} 2$, and 4D3 in human T-lymphocytes (Seybold et al., 1998) and toll-like receptor 4 (TLR4)-induced expression of PDE4B2 in human monocytes (Elwood et al., 2010). Of the eleven PDE families (PSE1-11), PDE4 is the primary cAMPspecific enzyme class. It consists of four genes (PDE4A-D), each with multiple variants encoding more than twenty protein products (Wittmann and Helliwell, 2013; Blanchard et al., 2014). PDE4s are the predominant cAMP-degrading isoenzymes in hematopoietic cells (Bjorgo and Tasken, 2006). In addition to their actions in immune cells, PDE4 isoforms are modulators of proinflammatory stress responses in pulmonary epithelial cells (Seybold et al., 1998; Wright et al., 1998), vascular endothelium, keratinocytes, smooth muscle, joint chondrocytes, synoviocytes (Houslay et al., 2005; Schett et al., 2010), and particular aspects of the central nervous system (Ashrafian et al., 2010; Martinez and Gil, 2014). The therapeutic potential of PDE4 inhibition in diseases such as chronic obstructive pulmonary disease (COPD), cystic fibrosis (CF) and asthma, has long been appreciated, with PDE4B up-regulation in airway epithelial cells being implicated in COPD pathogenesis (Michalski et al., 2012).

Increased intracellular cAMP levels activate cAMP-dependent protein kinase (PKA), that in turn activate certain transcription factors, such as cAMP-response element binding protein (CREB), but inhibit others, such as nuclear factor kappa B (NF-кB) (MacKenzie and Houslay, 2000). PKA does not appear to inhibit NF- $\mathrm{B}$-driven transcription by disrupting $\mathrm{IkB} \alpha$ degradation or NF- $\kappa \mathrm{B}$ DNA binding activity (Takahashi et al., 2002). Rather, NF- $\kappa$ B transcriptional activity may be inhibited either directly, through phosphorylation of the NF- $\mathrm{B}$ subunit, p65, on serine 536 of the C-terminal transactivation domain (p-p65) (Takahashi et al., 2002) and blocking p65 nuclear translocation (Abdollahi et al., 2011), or indirectly, through phosphorylation and competition for the transcriptional coactivator CREB binding protein (CBP), or its homologue, p300 (Parry and Mackman, 1997).

Phosphodiesterases are upregulated and activated in PS and $\mathrm{AD}$, and are implicated as key inducers of these and other inflammatory disorders (Smith et al., 2004; Schafer, 2012; Schafer et al., 2014). Aberrant expression and activation of PDE4 in keratinocytes and infiltrated leukocytes can promote PS, AD, and other conditions (Schafer et al., 2014) through immune-mediated inflammatory processes (Oger et al., 2005). While TLR activation, and production of prostaglandins can direct increased expression of PDEs, particularly PDE4 (Schafer et al., 2014), and EISO can suppress lipopolysaccharide (LPS)-mediated cyclooxygenase activity and cytokine/chemokine expression (Sharma et al., 2014), whether EISO can also block LPS-induced stress responses, such as PDE activation, is unknown. In this report we test the hypothesis that EISO may suppress these pro-inflammatory responses through inhibition of cAMP-degrading PDEs and subsequent promotion of cAMP-mediated NF- $\kappa$ B activation. We demonstrate that EISO can provide symptom relief for pediatric $\mathrm{AD}$ patients, and that EISO can suppress chronic inflammatory psoriatic skin conditions by suppressing PDE4 and 7 expression, and total PDE and NF-кB activation, in skin, blood, and lung cancer models. These results suggest that EISO may be a novel therapeutic agent for treating chronic and acute inflammatory disorders, such as PS and AD, and other inflammatory diseases.

\section{MATERIALS AND METHODS}

\section{Phase 2 Clinical Trials for Treatment of AD/Eczema}

A single-center, open-label, proof-of-concept Phase 2 trial of a regimen of three topical EISO formulations containing $0.1 \%$ colloidal oatmeal for treatment of $\mathrm{AD} /$ eczema was conducted (Browning et al., 2017). The Western Institutional Review Board (WIRB) reviewed and approved the protocol and informed consent/assent documents before study start-up (WIRB Study number 20140941). All patients and/or legally authorized representatives provided written informed consent/assent, as applicable, prior to conduct of any study-related activities (WIRB Study Number is 1146975). The trial participants used a combination of bubble bath gel, soothing cream and daily cleanser for 60 days. Twenty five patients with mild, moderate or severe eczema were enrolled in the study, and 22 patients completed the treatment regimen. The patients were assessed for changes in their disease severity using changes in their Eczema Area and Severity Index (EASI) scores as described in Hanifin et al. (2001) and Leshem et al. (2015).

\section{Cell Culture}

Primary cultures of human dermal fibroblast (DF), BEAS-2B immortalized human bronchial epithelial cells, and A549 cells (an alveolar type II epithelium-like cell line derived from a lung adenocarcinoma) were maintained in DMEM supplemented with 5\% (v/v) FBS (Invitrogen, Carlsbad, CA, United States). THP-1 human acute monocytic leukemia cells were maintained in RPMI 
(Invitrogen)/5\% (v/v) FBS. All cultures were maintained in a $37^{\circ} \mathrm{C}, 5 \% \mathrm{CO}_{2}$ atmosphere.

\section{Experimental EISO Formulation}

Pharmaceutical-grade EISO (lot: PISO-110904SD/SA) was obtained from Santalis Pharmaceuticals, Inc. (San Antonio, TX, United States). Constituent analysis and its compliance with the international standard for Indian sandalwood oil (ISO 3518:2002) has been previously reported (Sharma et al., 2017). EISO was diluted in dimethyl sulfoxide (DMSO) as a $10 \%(\mathrm{v} / \mathrm{v})$ stock. The equivalent volumes of DMSO used as vehicle controls had no adverse effects on the cells.

\section{Human Full-Thickness Skin Model}

Reconstituted full-thickness normal human skin and psoriatic phenotype organoid models (MatTek Corp., Ashland, MA, United States) were incubated in the manufacturer's assay media (Grossman et al., 1989; Nograles et al., 2008) supplemented with or without EISO at 0.001 or $0.002 \%(\mathrm{v} / \mathrm{v})$. Media, with or without supplementation, were changed every second day. On day four, specimens were collected for histologic and immunohistochemistry (IHC) analysis.

\section{Antibodies and Reagents}

NF- $\kappa$ B p-p65 monoclonal antibody (93H1) was from Cell Signaling Tech (Danvers, MA, United States), and PDE4 polyclonal antibody (ab14628) was from Abcam (Cambridge, United Kingdom). The BIOMOL Cyclic Nucleotide PDE Assay kit was from ENZO Life Sciences, Inc. (Farmingdale, NY, United States). LPS (Escherichia coli 0111:B4) and 3-isobutyl1-methylxanthine (IBMX) were from Sigma-Aldrich (St. Louis, MO, United States), and rolipram was a gift from MedChem Express (Monmouth Junction, NJ, United States).

Immunohistochemistry staining of reconstituted psoriatic and normal tissue models was conducted using deparaffinized sections subjected to antigen retrieval, followed by incubation with anti-PDE4 primary antibody (1:100). Bound antibody was detected by DAB staining using a Ventana universal secondary antibody (Ventana Medical System, Tuscan, AZ, United States). All stained slides were digitally imaged at magnification equivalent to $20 \times$. Random fields were scored by an independent pathologist.

\section{CAMP PDE Activity}

Total cAMP PDE activity was determined from lysates of DF, BEAS-2B, A549, and THP-1 cell at 2 and $4 \mathrm{~h}$ following stimulation with LPS (1 $\mu \mathrm{g} / \mathrm{ml})$, and EISO (0.001-0.002\%), or IBMX or rolipram $[10 \mu \mathrm{M}$; concentrations previously demonstrated to saturate for PDE inhibition (Cox et al., 1999; Oger et al., 2005)]. PDE activity was assessed using a colorimetric cyclic nucleotide phosphodiesterase assay (Enzo Life Sciences) following manufacturer's protocol, and expressed as pmol phosphate generated per min relative to the activity of a supplied bovine brain PDE preparation standardized to total cell lysate protein content determined using the Pierce BCA protein assay kit (Thermo Fisher Scientific, San Jose, CA, United States).
In vitro PDE activity was assessed by modification of the Enzo Life Sciences' cyclic nucleotide PDE assay kit. Briefly, EISO (0.001-0.002\%) was added to the bovine brain PDE preparation (20 mUnits; 1 Unit $=$ hydrolysis of $1 \mathrm{nM} \mathrm{cAMP}$ per $\min$ at $30^{\circ} \mathrm{C}$, $\mathrm{pH} 7.4$ ) and incubated in the presence of assay buffer, cAMP, and $5^{\prime}$-nucleotidase for $30 \mathrm{~min}$ at room temperature. The reaction was terminated by adding BIOMOL Green reagent and the resulting Abs. $\mathrm{OD}_{620} \mathrm{~nm}$ was expressed as enzymatic activity relative to a standard curve of the bovine brain PDE preparation.

\section{Immunofluorescence}

Cells were grown on cover slips overnight, fixed in $4 \%(\mathrm{w} / \mathrm{v})$ PBS-buffered paraformaldehyde, and permeabilized in $0.1 \%$ Triton X-100 phosphate buffered saline (Bio-Rad). Cells were then incubated with primary p-p65 (1:200) and visualized with Alexa Fluor 488 goat anti-rabbit IgG secondary antibody (1:1,000 Thermo Fisher Scientific; A-11008) and counterstained with rhodamine-conjugated phalloidin (1:500, Thermo Fisher Scientific; R415). Cover slips were mounted on microscopic slides using DAPI-Mounting Medium (Vector Laboratories, Inc., Burlingame, CA, United States; H-1200) and imaged as single mid-cell confocal planes using a $40 \times$ objective on an LSM 780 confocal microscope (Carl Zeiss, Canada).

\section{Enzyme-Linked Immunosorbent Assays (ELISAs)}

Sandwich enzyme-linked immunosorbent assays (ELISAs) for TNF- $\alpha$, MCP-1, IL-6, and IL-8, CXCL5 (Ray Biotech, Inc., Norcross, GA, United States), were performed on culture media from LPS stimulated DF, BEAS-2B, A549, and THP-1 cells (with and without treatment with EISO) according to manufacturer's instructions. ELISAs for p-p65 and total p65 (RayBiotech, Inc.; PEL-NF-кB P65 S536) were performed using cell lysates from DF, BEAS-2B, A549, and THP-1 cells \pm LPS/EISO under conditions indicated in the figure legend. Standard curves were constructed with supplied standards to allow conversion of $\mathrm{Abs}_{\mathrm{OD}} \mathrm{D}_{450} \mathrm{~nm}$ readings of experimental samples to $\mathrm{pg} / \mathrm{ml}$ of the respective factors.

\section{Quantitative Real-Time PCR (qRT-PCR) for mRNA Expression of PDE Isoforms}

Total RNA was isolated from DF, BEAS-2B, A549, and THP-1 cells using RNeasy kit (QIAGEN, MD, United States) according to the vendor's protocol. cDNA was synthesized using Super Script First-Strand synthesis system for RT-PCR (Invitrogen). PDE4A, PDE4B, PDE4C, PDE4D, PDE7A, and PDE7B were amplified using real-time PCR system ABI-PRISM 7900 (Applied Biosystems, Foster City, CA, United States). Primers were designed as follows: PDE4A forward, 5'-GCTGAAGA CCTCATCGTAAC-3'; reverse, 5'-ATTCTGTTTGTCCAGG AATG-3'; PDE4B forward, 5' ${ }^{\prime}$-ATTCTGTTTGTCCAGGAAT G-3'; reverse, 5'-ATGCTGGTGTAGAAAGGAGA-3'; PDE4C, forward, 5'-AGAGTGGTACCAGAGCAAGA-3'; and reverse, 5'-TGGGAGCCACCTATAACTAA-3'. PDE4D forward, 5'-CA CCAAATGACCTTACCTGT-3'; reverse, 5' -AGCTCCACTGTT ACCTTTCA-3'; PDE7A, 5'-GCAATATGAATTTGGCTTTC-3'; 
reverse, 5'-GGAAAGAGCTGCAGTCTAAA-3'; PDE7B forward, 5' -TCTTCAATACCCATGGACTC-3' ${ }^{\prime}$; reverse, $5^{\prime}$-ATCCT GTGTCATTTCCTTTG-3'; 18S RNA forward, 5'-CGATGCT CTTAGCTGAGTGT-3'; reverse, 5'-GGTCCAAGAATTTCAC CTCT-3'. Target gene expression was normalized to $18 \mathrm{~S}$ mRNA levels in respective samples as an internal standard and relative transcript quantity was calculated using the $\Delta \Delta \mathrm{Ct}$ method of Applied Biosystems as previously described (Becker-Santos et al., 2012).

\section{Statistical Analysis}

Phosphodiesterase activity, qRT-PCR, and ELISA assay results were compared using a one-way analysis of variance (ANOVA) followed by a Bonferroni post-test comparing only the pairs of interest if ANOVA $p$-values were significant. The post-test results are shown as ${ }^{*} p<0.05,{ }^{* *} p<0.01$, and ${ }^{* * *} p<0.001$ versus vehicle-treated and PDE enzyme-negative controls; ${ }^{\dagger} p<0.05$, ${ }^{\dagger \dagger} p<0.01,{ }^{\dagger \dagger \dagger} p<0.001$ versus LPS-stimulated and PDE enzymepositive alone controls.

\section{RESULTS}

\section{Phase 2 Clinical Trial of EISO to Treat AD}

Twenty-five pediatric patients with mild, moderate or severe AD were treated with an EISO-containing regimen over an 8-week course and assessed for changes in their disease severity using the EASI scoring method (Figure 1A). All but one patient (who had an allergic reaction to carpet cleaning solution prior to their final visit) showed an improvement in their condition. $87.5 \%$ of patients met the primary endpoint of the study (a 25\% reduction in their EASI score) and there were no adverse events or safety issues with the treatment. The average reduction in overall scores was $67.8 \%$ (average of 6.2 EASI score reduction per patient), with $75 \%$ of patients achieving a $>50 \%$ reduction in their score. $18.8 \%$ experienced a complete remission of their symptoms (a $100 \%$ reduction in EASI score). A representative patient is shown before and after treatment (Figure 1B).

\section{EISO Suppresses LPS-Induced PDE Activity}

The clinical responses to EISO treatment of $\mathrm{AD}$, and links between $\mathrm{AD}$ and PDEs described above, compelled us to examine whether EISO might affect cellular PDE activity in a panel of cell types. DF was used as established models for LPSstimulated inflammatory responses that can be suppressed by EISO treatment (Sharma et al., 2014). THP-1 cells were used to model infiltrated leukocytes (Schafer et al., 2014). BEAS-2B cells were used to model upregulated PDE4B expression in airway epithelial cells as a contributor to the pathogenic inflammatory response of COPD (Michalski et al., 2012; Blanchard et al., 2014). A549 cells were used as a lung cancer model, since lung cancer is a frequent comorbidity in COPD and therefore share common pathogenic pathways (Adcock et al., 2011; Yang et al., 2011) including the therapeutic potential of PDE4 targeting (Pullamsetti et al., 2013).
A

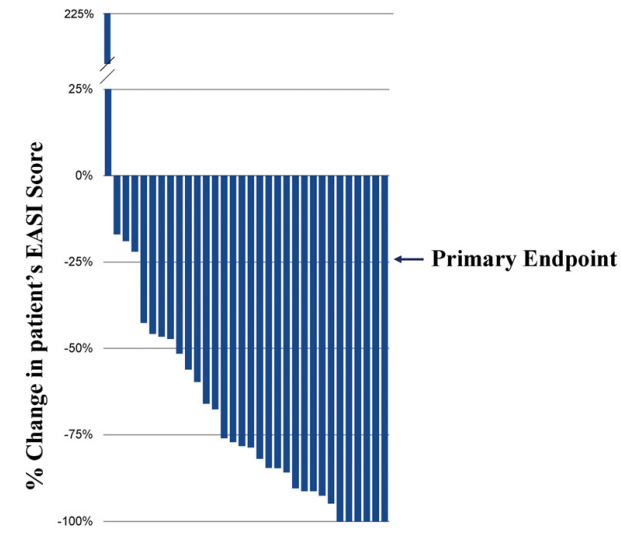

B

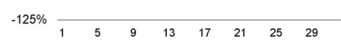

Trial Participants
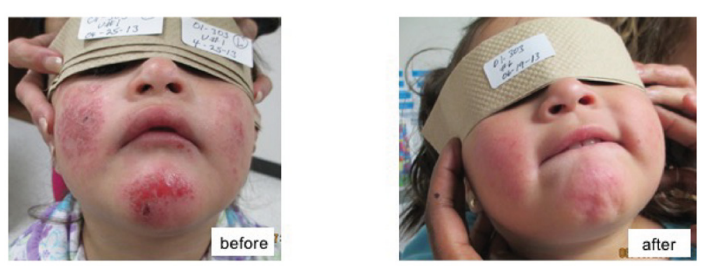

FIGURE 1 | Phase 2 Clinical Trials for treatment of atopic dermatitis (AD) and psoriasis. (A) Percentage change in patients' EASI scores over 8 weeks (ranked, $n=32$ ). (B) Representative patient with severe AD (eczema) before (left) and after (right), 8 weeks of treatment with the East Indian sandalwood oil (EISO)-containing regimen. "Written informed consent was obtained from the individual for the publication of this image."

Total cAMP PDE activity was determined from cell lysates at 2 and $4 \mathrm{~h}$ after stimulating with LPS \pm EISO (Figure 2). PDE activity in DF increased $\sim 2.5$-fold after LPS exposure, while co-treatment with EISO, suppressed LPS-mediated PDE activity dose- and time-dependently, and to levels comparable to that observed in the control sample at $0.002 \%$ (Figure 2A). While LPS modestly increased PDE activity in BEAS-2B cells (up to 1.7-fold at $4 \mathrm{~h}$ ), EISO suppressed LPS-mediated PDE activity at $0.001 \%$, and to below basal levels of the control samples at $0.002 \%$ (Figure 2B). PDE activity in LPS-stimulated A549 cells was also modestly increased $(\sim 1.6$-fold at $4 \mathrm{~h})$, and EISO treatment suppressed LPS-mediated PDE activity by at least twofold, and to levels up to a third of the basal level observed in control samples (Figure 2C). PDE activity in THP-1 cells increased $\sim$ twofold after LPS exposure, and EISO treatment dose- and time-dependently suppressed LPS-mediated PDE activity to levels indistinguishable from that of the control sample at $0.002 \%$ EISO (Figure 2D). These observations suggest that EISO can antagonize both induced and chronic PDE activity in a spectrum of cell types.

\section{Pharmacological Characterization of PDE Inhibition by EISO}

Phosphodiesterases are indicated as inducers of PS and AD inflammatory disorders (Smith et al., 2004; Schafer, 2012; 
A

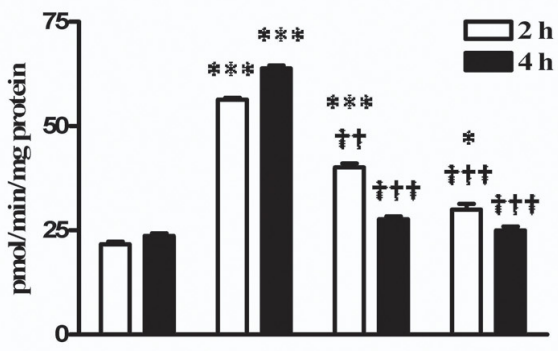

C

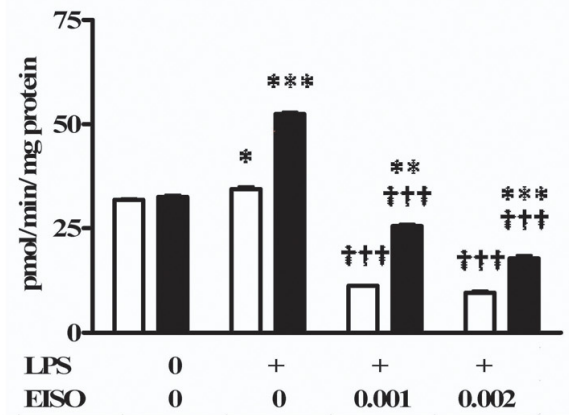

B

BEAS-2B

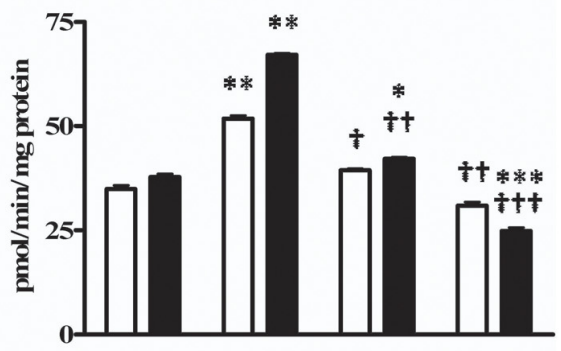

D

THP-1

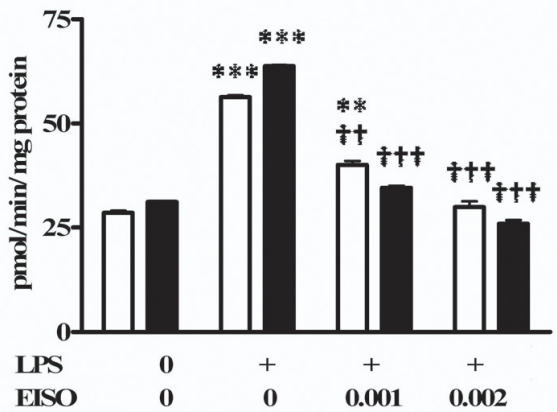

FIGURE 2 | East Indian sandalwood oil suppresses lipopolysaccharide (LPS) induced phosphodiesterase (PDE) activity in cell models. (A) dermal fibroblast (DF), (B) BEAS-2B, (C) A549, and (D) THP-1 cells were treated with vehicle (0), LPS (1 $\mu \mathrm{g} / \mathrm{ml})$ or LPS + EISO at 0.001 or $0.002 \%$ ( $/ \mathrm{v}$ ) for $2 \mathrm{~h}$ (open bars) and $4 \mathrm{~h}$ (filled bars). Cyclic adenosine monophosphate (cAMP) PDE activity was determined from cell lysates as described in "Materials and Methods." All values are given as the mean \pm SEM $(n=4) .{ }^{*} p<0.05,{ }^{* *} p<0.01$, and ${ }^{* * *} p<0.001$ versus unstimulated control; ${ }^{\dagger} p<0.05,{ }^{\dagger \dagger} p<0.01,{ }^{\dagger \dagger \dagger} p<0.001$ versus LPS-stimulated cells.
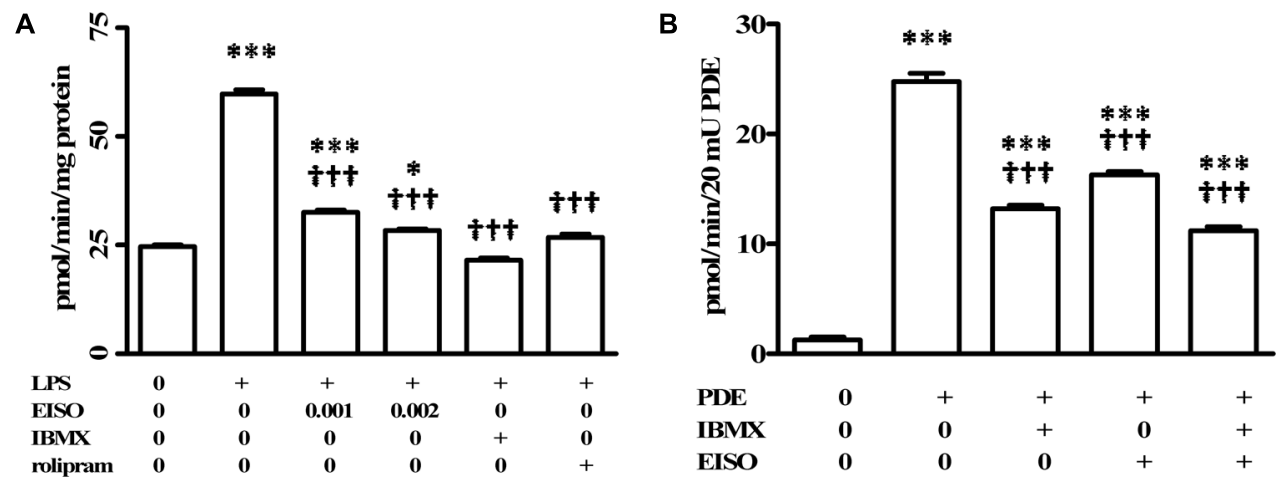

FIGURE 3 | Pharmacological characterization of CAMP-PDE activity in LPS induced THP-1 cells. (A) THP-1 cells were treated with vehicle (0), LPS (1 $\mu \mathrm{g} / \mathrm{ml})$ or LPS + EISO $(0.001$ or $0.002 \%)$ or LPS + IBMX $(10 \mu \mathrm{M})$ or LPS + rolipram $(10 \mu \mathrm{M})$ for $4 \mathrm{~h}$. c-AMP PDE activity was determined in the cell lysate as described in Materials and Methods. Data are mean $\pm \operatorname{SEM}(n=4) .{ }^{*} p<0.05,{ }^{* *} p<0.01$, and ${ }^{* * *} p<0.001$ versus unstimulated control; ${ }^{\dagger} p<0.05,{ }^{\dagger \dagger} p<0.01,{ }^{\dagger \dagger \dagger} p<0.001$ versus LPS-stimulated cells. (B) The ability of EISO to directly inhibit PDE was assessed in vitro by modification of the cyclic nucleotide phosphodiesterase assay kit as described in Materials and Methods, in vehicle control (0), bovine brain PDE $(20 \mathrm{mU})$ alone, or + IBMX (10 $\mu \mathrm{M})$, EISO (0.002\%), or IBMX + EISO. Data are presented as mean \pm SEM $(n=3) .{ }^{*} p<0.05,{ }^{* *} p<0.01$, and ${ }^{* * *} p<0.001$ versus no PDE control; ${ }^{\dagger} p<0.05,{ }^{+\dagger} p<0.01,{ }^{\dagger \dagger \dagger} p<0.001$ versus PDE alone.

Schafer et al., 2014), with PDE4 being specifically identified as induced in keratinocytes and infiltrated leukocytes of PS, and AD lesions (Oger et al., 2005; Schafer et al., 2014). In order to assess the contribution of PDE4 to the EISO attenuation of LPSstimulated total cellular cAMP hydrolysis activity, suppression of total cellular cAMP PDE activity in EISO treated, LPS-stimulated THP-1 cell lysates was compared to that of cells treated with IBMX as a non-specific PDE inhibitor, or rolipram as a selective PDE4 inhibitor (Figure 3A). IBMX and rolipram suppressed cAMP hydrolytic activity to levels comparable to that of control 
and EISO-treated lysates, with the non-specific PDE inhibitor being $\sim 20 \%$ more efficacious.

The ability of EISO to mimic PDE inhibition by IBMX and rolipram in LPS-stimulated lysates suggested that EISO might directly inhibit PDE activity. We therefore assessed whether EISO could suppress the cAMP hydrolysis activity of bovine brain PDE (Figure 3B). 20 mUnits (mU) of this PDE preparation resulted in cAMP hydrolysis 25-times greater than that of buffer control. IBMX and EISO both suppressed this activity approximately $50 \%$ and the combination of EISO and IBMX only marginally further suppressed PDE activity. These results parallel the impact of EISO and IBMX on lysate cAMP hydrolysis activity seen in Figures 2, $3 \mathrm{~A}$, and suggest that EISO can efficiently antagonize potent acute PDE activation by LPS and inhibit PDE activity directly to levels comparable to that of a broad-spectrum, and a PDE4-selective, PDE inhibitor.

\section{Impact of EISO on LPS-Induced PDE Isoform Transcription}

Since PDEs are known to be transcriptionally upregulated by a variety of proinflammatory stresses (Smith et al., 2004; Oger et al., 2005; Schafer et al., 2014), the ability of EISO to modulate LPSstimulated expression of the major cAMP hydrolyzing PDEs was assessed in DF by measuring expression of PDE4A-D, 7A and 7B by qRT-PCR (Figure 4). LPS stimulation resulted in a twentyto fivefold increase in pro-PDE4A-D expression, and a twentyand sixfold increase in pro-PDE7A and B, respectively. EISO substantially inhibited expression of LPS-induced pro-PDE4A, $\mathrm{B}$ and $\mathrm{D}$, and $7 \mathrm{~B}$, such that at $0.002 \%$, transcript levels were at or below basal levels. Additionally, pro-PDE7A levels were suppressed to $\sim$ threefold above basal levels at $0.002 \%$ EISO. Although pro-PDE4C expression was reduced $\leq 25 \%$ by EISO treatment, overall, these results indicate that EISO can suppress both expression and activation of the major cAMP hydrolase enzymes in response to acute LPS stimulation.

\section{EISO Suppresses PDE4 Expression in Reconstituted Psoriatic Human Skin Organoid}

We previously reported that EISO can revert the psoriatic phenotype of a reconstituted organotypic psoriatic skin model (Sharma et al., 2017). Since PDE4 expression is known to be upregulated in hyperplastic skin epidermis (Morizane and Gallo, 2012), we assessed PDE4 expression and distribution in this psoriasis model as well (Figure 5). After 4 days of culture, the normal skin model exhibited defined keratinocyte layers with PDE4 expression localized predominantly as light staining of stratum basalis (Figure 5A), while the psoriatic skin model exhibited a thickened stratum basalis layer with Rete ridges and elevated PDE4 expression in the disorganized stratum spinosum and granulosum layers (Figure 5B). When treated with EISO for 4 days, the psoriatic skin model exhibited well-defined epidermal layers with PDE4 expression being predominantly localized to the stratum basalis and suppressed to levels below that observed in the normal skin model (Figure $5 \mathrm{C}$ ). These results indicate that the clinical observations above could be recapitulated in an ex vivo skin assay, and correlate restoration of normal skin phenotype by EISO to its ability to suppress PDE4 expression.

\section{EISO Suppresses LPS-Induced TNF- $\alpha$, MCP-1, IL-6, and IL-8 Production}

Since PDE activation is linked to proinflammatory responses, the anti-inflammatory properties of EISO were assessed on LPSinduced secretion of key cytokine/chemokine related factors (TNF- $\alpha$, MCP-1, IL-6, and IL-8) in skin (DF), lung (BEAS$2 \mathrm{~B}$ and A549), and monocytic (THP-1) cells (Figure 6). Using conditions previously established for induction of these cytokine/chemokines in DF and keratinocytes by LPS (Sharma et al., 2014, 2017), we observed that conditioned media contained substantially elevated levels of all four factors in these four cell lines, and that chemokine/cytokine accumulation was dosedependently suppressed by EISO to approaching 90\%. The robust suppression key cytokine-related factors production indicates that the ability of EISO to suppress proinflammatory cytokine/chemokine production is conserved across a variety of cell types.

\section{EISO Suppresses LPS-Stimulated NF-kB Activation}

TNF- $\alpha$, MCP- 1 , IL- 6 , and IL- 8 are well characterized NF- $\kappa B$ transcriptional targets (Tang et al., 2017). We therefore assessed the impact of EISO treatment on NF- $\mathrm{BB}$ activation by measuring p-p65 levels in LPS-stimulated DF, BEAS-2B, A549, and THP-1 cells. Using an ELISA assay, all four cell lines exhibited sustained NF- $\mathrm{BB}$ activation after $48 \mathrm{~h}$, while co-treatment with EISO suppressed LPS-mediated NF- $\kappa$ B activation by up to $90 \%$ in DF cells, to unstimulated levels in THP-1 cells and to levels less than or equal to that observed in control samples of BEAS2B and A549 cells (Figure 7). These results were validated by immunofluorescence analysis of p-p65 expression and subcellular localization demonstrating increased nuclear p-p65 induced by LPS, and the blunting of this phenomenon by EISO at 0.001 and $0.002 \%$. These results indicate the anti-inflammatory activity of EISO includes inhibiting activation of this central stress response modulator.

\section{DISCUSSION}

Erythroderma, a hallmark of inflammatory skin diseases such as $\mathrm{PS}$ and $\mathrm{AD}$, results from immune dysregulation that leads to infiltration of inflammatory cells into the skin, interaction of cytokines, chemokines, intercellular adhesion molecules, and increased turnover of keratinocytes (Sigurdsson et al., 2000). Current treatments include emollients, vitamin D supplementation, topical calcineurin inhibitors, and topical corticosteroids (TCS) (Weidinger and Novak, 2016). Although effective, TCS may cause adverse effects, including increased susceptibility to infections and skin atrophy, and failure to respond to these topical agents can lead to patients being treated with biologics, most commonly an anti-TNF- $\alpha$ inhibitor. Biologics are expensive and require repeated injections; hence, the quest for less 
A

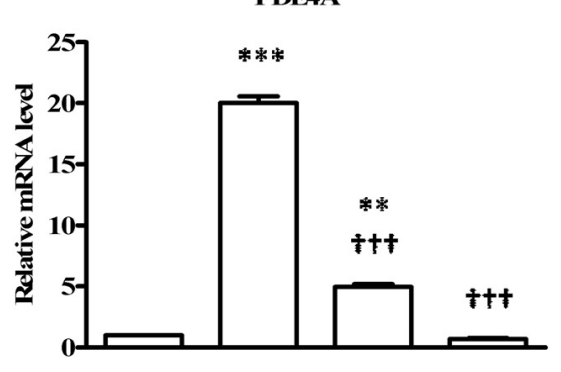

B

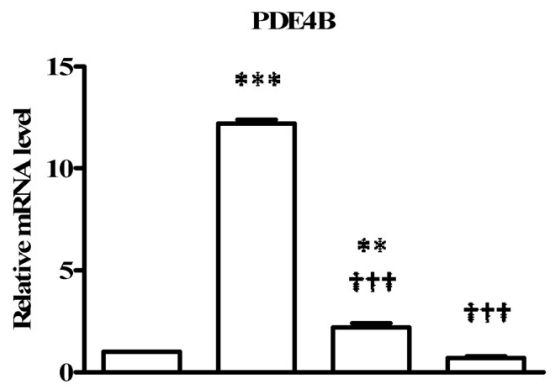

C

c

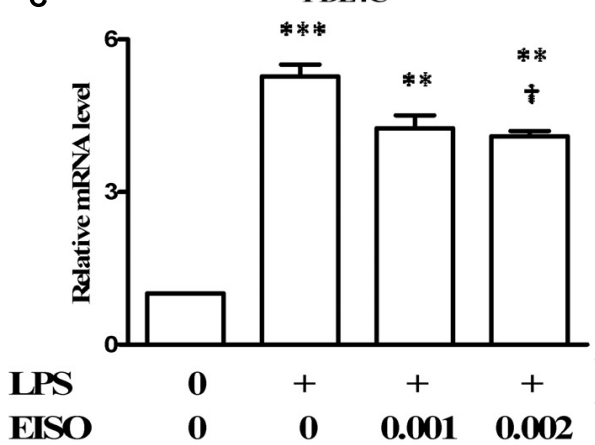

D

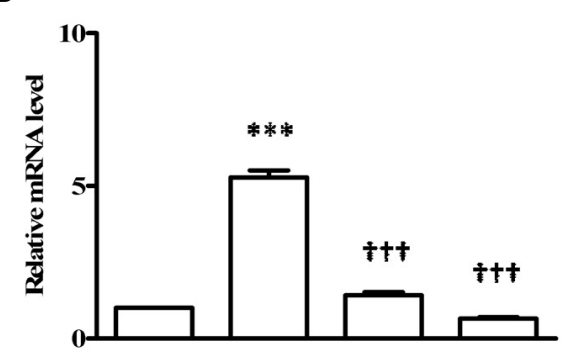

E

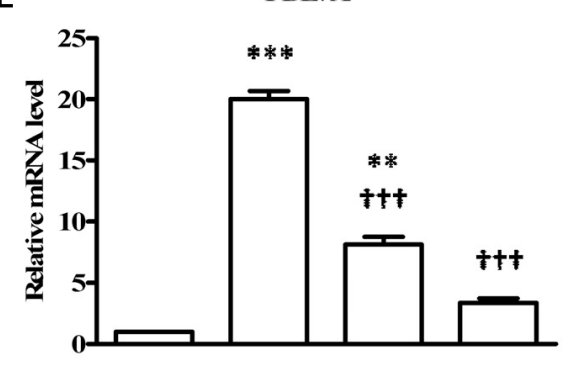

$\mathbf{F}$

PDE7B

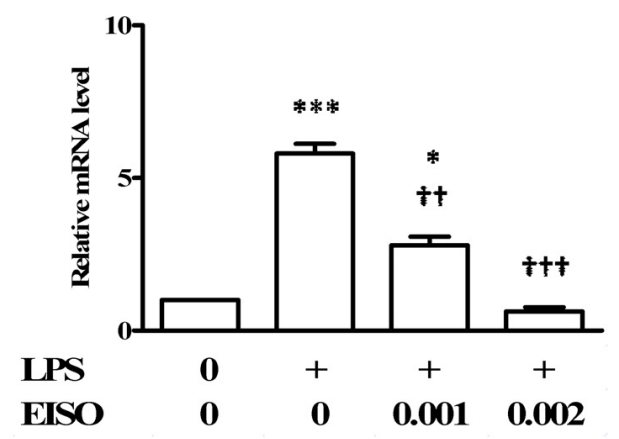

FIGURE 4 | East Indian sandalwood oil suppresses expression of CAMP hydrolyzing PDE 4 isoforms. DFs were treated with vehicle control (0), LPS (1 $\mu \mathrm{g} / \mathrm{ml})$ or LPS + EISO (0.001 or $0.002 \%)$ for 4 h. mRNA expression of PDE isoforms: (A) PDE4A, (B) PDE4 B, (C) PDE4C, (D) PDE4D, (E) PDE7A, and (F) PDE7B, were analyzed by qRT-PCR. Relative levels of expression from representative experiments repeated thrice with similar results were normalized to $18 \mathrm{r}$ rRNA level. All values are given as the mean \pm SEM $(n=4) .{ }^{*} p<0.05,{ }^{* *} p<0.01$, and ${ }^{* * *} p<0.001$ versus control; ${ }^{\dagger} p<0.05,{ }^{\dagger \dagger} p<0.01,{ }^{\dagger \dagger \dagger} p<0.001$ versus LPS-stimulated cells.

expensive alternatives is ongoing. Although the search for oral treatments has been dominated by kinase targets, small molecule PDE4 inhibitors, such as the recently approved drug, crisaborole, are generating much interest (Paller et al., 2016).

East Indian sandalwood oil has been used since antiquity as a traditional medicine, in aromatherapy, as an anti-inflammatory, astringent, antiseptic and anticancer (Dwivedi et al., 2005, 2006; Burdock and Carabin, 2008; Santha et al., 2013). Its antiseptic and anti-inflammatory properties have made it a popular traditional remedy for diverse skin problems. The anti-inflammatory benefit was shown in a phase 2 clinical study in fifty acne patients where $90 \%$ of patients showed improvement after 2 months of treatment (Moy et al., 2012). The treatment was well tolerated with a rapid reduction in reddened inflamed lesions. In addition, a similar open-label, proof of concept Phase 2 clinical trials of topical EISO formulations for treatment of AD (Browning et al., 2017) and psoriasis (Sharma et al., 2017) was found to be safe and well-tolerated and showed initial indications of efficacy. Anecdotally, the patient shown in Figure $\mathbf{1}$ also had a concomitant MRSA infection that was resolved by the treatment. Our report here that the vast majority of pediatric $\mathrm{AD}$ patients met the study's primary endpoint with no evidence of adverse events or safety issues now extends the efficacy of topical EISO to manage this dermal inflammatory pathology as well.

Although EISO's mechanisms of action are not completely elucidated, santalols derived from EISO have been shown to 


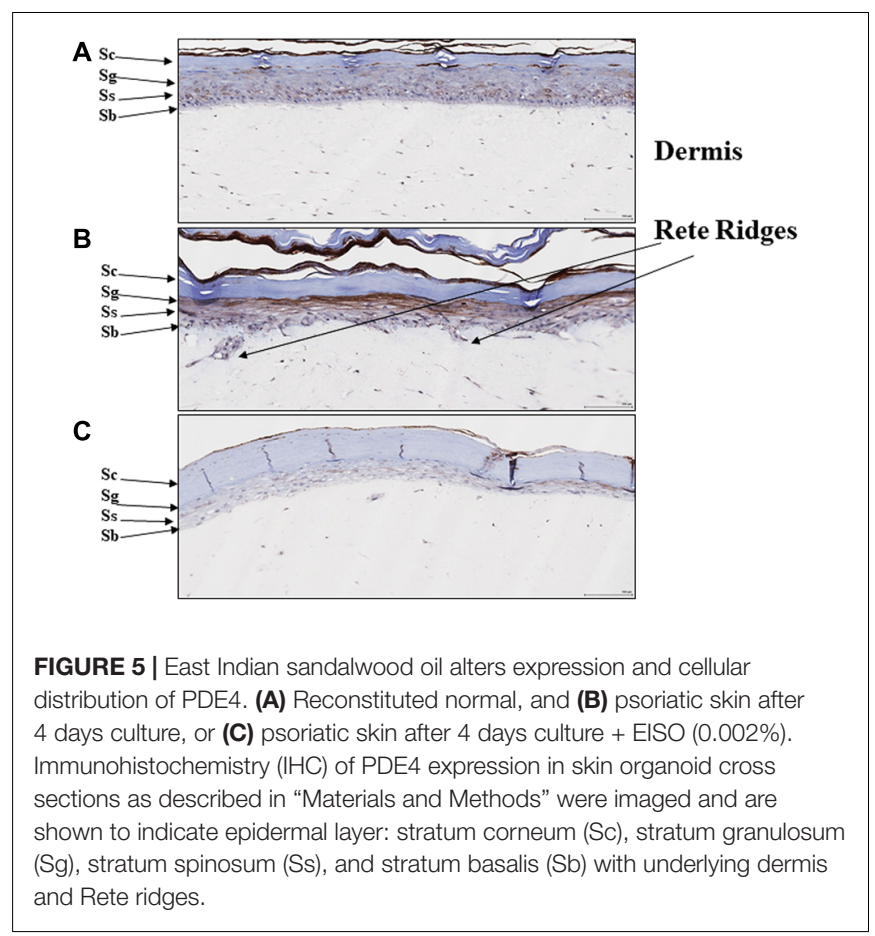

have substantial anti-inflammatory properties in skin models that are linked to suppression of prostaglandin and thromboxane production and cytokine/chemokine expression (Sharma et al.,
2014). PDE4 is reported to be a key modulator of proand anti-inflammatory mediators in both the immune (innate and adaptive) and non-immune cells (Zambon et al., 2005). LPS can stimulate an increase in total cellular PDE activity, and EISO can effectively block this PDE activation to levels comparable to that of samples treated with non-specific, and PDE4-specific inhibitors. While PDE4 and 7 are the predominant cAMP hydrolyzing classes found in immune cells, PDE4 is the dominant isoform in inflammatory cells and is highly expressed in cells of progressive psoriatic lesions (e.g., keratinocytes, vascular endothelium, and synovial membrane) (Schafer, 2012), and PDE4B is reported to be a major PDE activated by LPS stimulation (Oliva et al., 2012). Although we cannot conclude that the impact of EISO on PDE activity is an effect specific for a particular PDE subclass, our demonstration that EISO can antagonize LPS-stimulated transcript expression of PDE4 and 7 subclasses, and revert psoriatic pathology and expression of PDE4 is consistent with EISO's anti-inflammatory properties. Our observation that ESIO could specifically attenuate cAMP hydrolysis activity in an in vitro enzymatic assay in Figure 3B suggests that the suppressed cAMP hydrolysis activity by EISO or PDE-selective inhibitors in Figures 2, 3A was due to an effect on the enzymes themselves. The concomitant decreased expression of transcript levels of the best annotated cAMP hydrolyzing PDE isoforms, PDE4 and 7, by EISO treatment is consistent with the known upregulation of PDE expression in response to inflammatory stresses (Smith et al., 2004; Oger et al., 2005; Schafer et al., 2014) and previous reports that EISO is

\section{A}

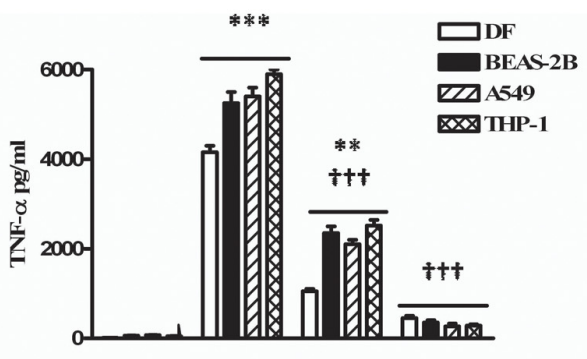

C

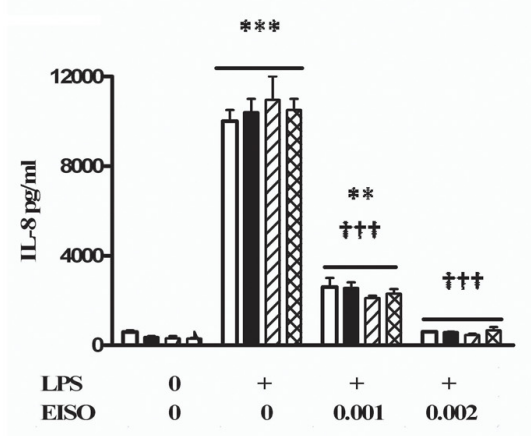

B

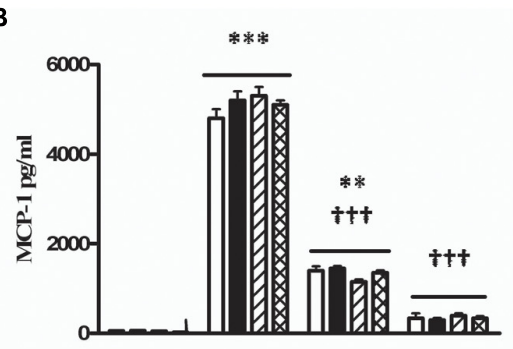

D

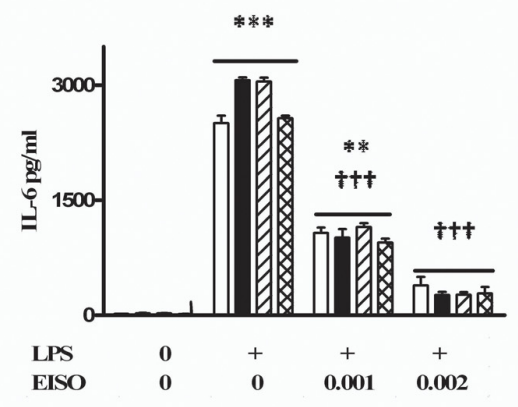

FIGURE 6 | Lipopolysaccharide stimulates and EISO suppresses sentinel cytokines/chemokines production by DF (open bar), BEAS-2B (filled bar), A549 (hatched

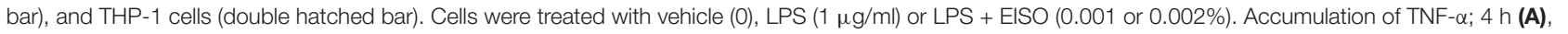
MCP-1 (B), IL-8 (C), and IL-6 (D) at $24 \mathrm{~h}$ was determined from conditioned media by ELISA. Cytokine/chemokine accumulation was compared with levels in LPS-stimulated samples, expressed as pg/ml. Data are mean \pm SEM $(n=4) .{ }^{*} p<0.05,{ }^{* *} p<0.01$, and ${ }^{* * *} p<0.001$ versus control; ${ }^{\dagger} p<0.05,{ }^{\dagger \dagger} p<0.01$, ${ }^{\dagger+\dagger} p<0.001$ versus LPS-stimulated cells. 


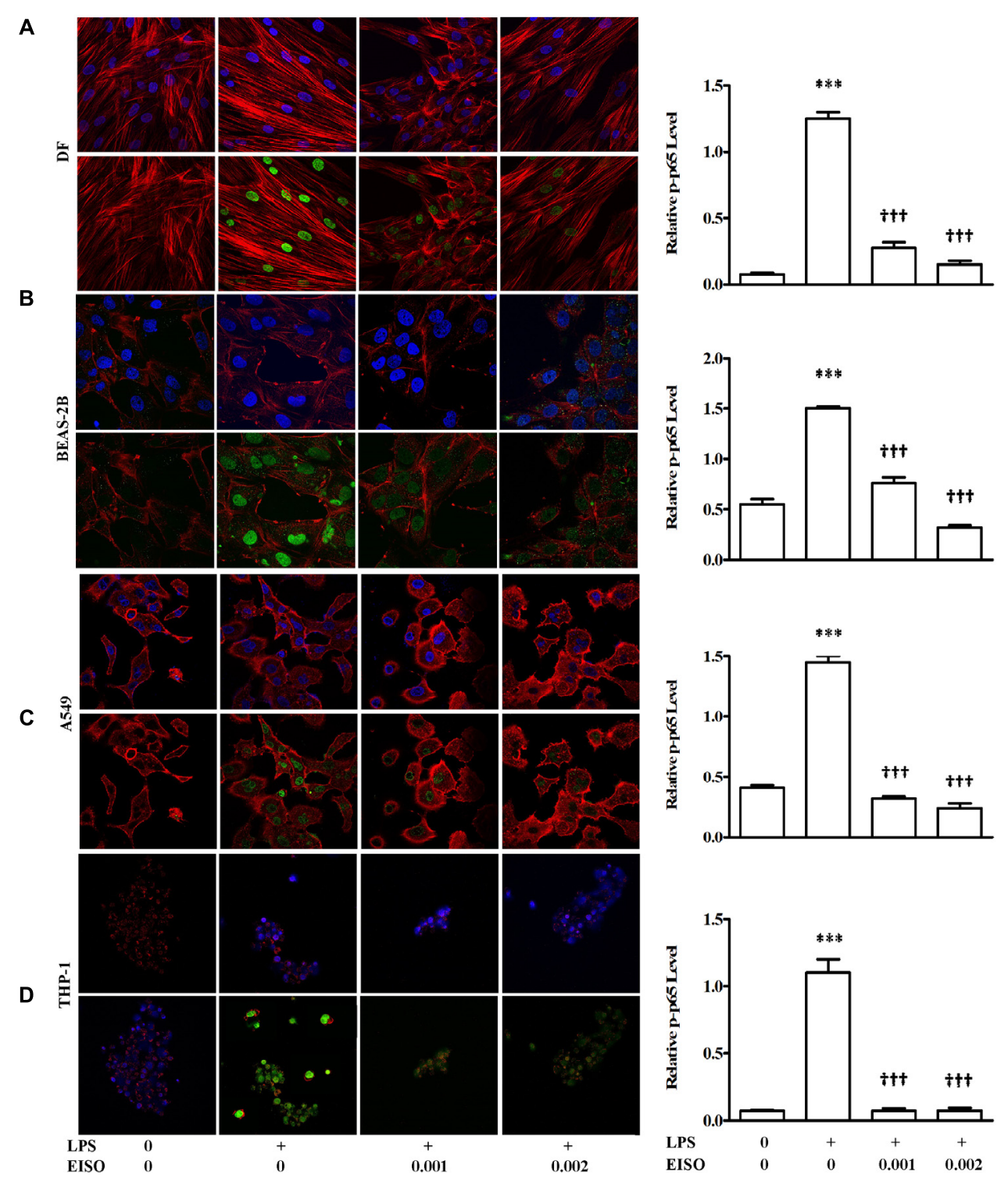

FIGURE 7 | East Indian sandalwood oil suppresses p-p65 expression in DF (A), BEAS-2B (B), A549 (C), and THP-1cells (D). Cells were treated with vehicle (0), LPS $(1 \mu \mathrm{g} / \mathrm{ml})$, LPS + EISO (0.001 or $0.002 \%)$ for $48 \mathrm{~h}$. Cells were stained for immunofluorescence imaging as described in Materials and Methods (left) to show p-p65 (green), actin filaments (red) and nuclei (blue). All stained slides were imaged using a $40 \times$ objective and identical post-capture magnification. p-p65 expression of all the four cell lines were also analyzed by ELISA (right). Data are mean \pm SEM $(n=4) .{ }^{*} p<0.05,{ }^{* *} p<0.01$, and ${ }^{* * *} p<0.001$ versus control; ${ }^{\dagger} p<0.05$, ${ }^{\dagger \dagger} p<0.01$, ${ }^{\dagger \dagger \dagger} p<0.001$ versus LPS-stimulated cells.

a potent anti-inflammatory agent (Sharma et al., 2014, 2017; Bommareddy et al., 2017). Our demonstration of the ability of EISO to modulate protein expression and distribution of PDE4 in organoids by IHC (Figure 5) supports the observed EISO-mediated suppression of PDE4 transcription and indicates that EISO can suppress both activity and expression of PDE4 isoforms.

Numerous studies that describe increased PDE4 expression and cAMP hydrolysis in inflammatory syndromes. Initial studies have shown that exposure of human monocytes to LPS leads to increase in mRNA levels and increased PDE4 activity
(Kotera et al., 1997; van Staveren and Markerink-van Ittersum, 2005). Similar LPS stimulation of PDE4 expression and CAMP hydrolysis activity has been demonstrated in murine PBMC and macrophages (Lugnier et al., 1999), this response was completely absent in PDE4-deficient mice (Jin and Conti, 2002). Increased PDE4 activity occurs in experimental models of systemic LPS response (Koga et al., 1995; Guo et al., 2014), and, as we have also shown here, PDE inhibitors reduce LPS-induced synthesis and release of cytokines (Dousa, 1999). The PDE4-selective inhibitor, cilomilast, is demonstrated to be effective treatments for COPD (Ouagued et al., 2005), while the first PDE4-selective inhibitor, 
rolipram, decreases LPS-induced lung neutrophilia in rodent models (Miotla et al., 1998; Toward and Broadley, 2001). The PDE-selective inhibitor, rolipram, is known to block ethanolinduced cAMP hydrolysis and NF- $\mathrm{B}$ signaling (Gobejishvili et al., 2008). NF- $\kappa \mathrm{B}$ is an essential transcriptional regulator of tumorigenesis, apoptosis, viral replication, inflammatory responses and various autoimmune diseases (Baldwin, 1996) and is part of stress responses activated by stimuli including pharmacologic agents, UV, bacterial cell wall components, growth factors and cytokines (An et al., 2002).

This first report that EISO is able to suppress LPS-stimulated $\mathrm{NF}-\kappa \mathrm{B}$ activation and resulting cytokine and chemokine expression, and to decrease transcription and activation of PDEs, suggest that EISO can antagonize proinflammatory stimuli by inhibiting the ability of PDEs to hydrolyze cAMP and thus allowing for PKA-mediated attenuation of NF- $\kappa$ B activation. In addition, to demonstrating the benefit of an anti-PDE activity for managing inflammatory dermal pathologies, this raises the possibility that targeting PDE4 and/or 7 could be exploited as an alternative therapeutic approach that might reduce side effects associated with targeting other PDE family members. The promising preliminary clinical trials results indicating the efficacy of EISO therapies to manage inflammatory skin disorders together with the ability of EISO to decrease NF- $\mathrm{B}$ activation by suppressing proinflammatory stimulation of PDE transcription, and directly suppressing PDE enzymatic activity, provides a strong rationale for continued study of EISO as a potential new

\section{REFERENCES}

Abdollahi, A., Morteza, A., Khalilzadeh, O., and Ahmadzadeh, A. (2011). Factor VIII concentration is greater in female than male patients with HIV infection. Int. J. Hematol. 93, 53-58. doi: 10.1007/s12185-010-0736-0

Adcock, I. M., Caramori, G., and Barnes, P. J. (2011). Chronic obstructive pulmonary disease and lung cancer: new molecular insights. Respiration 81, 265-284. doi: 10.1159/000324601

An, H., Yu, Y., Zhang, M., Xu, H., Qi, R., Yan, X., et al. (2002). Involvement of ERK, p38 and NF- $\kappa$ B signal transduction in regulation of TLR2, TLR4 and TLR9 gene expression induced by lipopolysaccharide in mouse dendritic cells. Immunology 106, 38-45. doi: 10.1046/j.1365-2567.2002.01401.x

Arkwright, P. D., Motala, C., Subramanian, H., Spergel, J., Schneider, L. C., Wollenberg, A., et al. (2013). Management of difficult-to-treat atopic dermatitis. J. Allergy Clin. Immunol. Pract. 1, 142-151. doi: 10.1016/j.jaip.2012. 09.002

Ashrafian, H., O'Flaherty, L., Adam, J., Steeples, V., Chung, Y. L., East, P., et al. (2010). Expression profiling in progressive stages of fumarate-hydratase deficiency: the contribution of metabolic changes to tumorigenesis. Cancer Res. 70, 9153-9165. doi: 10.1158/0008-5472.CAN-10-1949

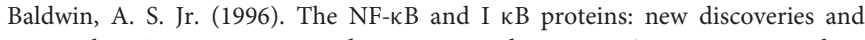
insights. Annu. Rev. Immunol. 14, 649-683. doi: 10.1146/annurev.immunol.14. 1.649

Becker-Santos, D. D., Guo, Y., Ghaffari, M., Vickers, E. D., Lehman, M., Altamirano-Dimas, M., et al. (2012). Integrin-linked kinase as a target for ERG-mediated invasive properties in prostate cancer models. Carcinogenesis 33, 2558-2567. doi: 10.1093/carcin/bgs285

Bjorgo, E., and Tasken, K. (2006). Role of cAMP phosphodiesterase 4 in regulation of T-cell function. Crit. Rev. Immunol. 26, 443-451. doi: 10.1615/ CritRevImmunol.v26.i5.40

Blanchard, E., Zlock, L., Lao, A., Mika, D., Namkung, W., Xie, M., et al. (2014). Anchored PDE4 regulates chloride conductance in wild-type and DeltaF508CFTR human airway epithelia. FASEB J. 28, 791-801. doi: 10.1096/fj.13-240861 therapeutic for the treatment of inflammatory skin conditions such as PS and AD.

\section{AUTHOR CONTRIBUTIONS}

MC, MS, and CL were responsible for study design. MS and MC were performed all in vitro studies. JB and $\mathrm{EB}$ were conducted the clinical study. Santalis Pharmaceuticals, Inc. (CL, IC, and PC) provided EISO for the experimental use and designed the clinical study. Manuscript was written by MC, MS, and CL and all other authors provided editorial advice.

\section{FUNDING}

The clinical trial was sponsored by Santalis Pharmaceuticals, Inc. Laboratory studies were supported by a collaborative research agreement between MC and Santalis Pharmaceuticals, Inc. (UBC-F1502441).

\section{ACKNOWLEDGMENTS}

Histology support was provided by the Terry Fox/Vancouver Prostate Centre pathology core. Dr. Ladan Fazli provided pathology analysis.

Bommareddy, A., Brozena, S., Steigerwalt, J., Landis, T., Hughes, S., Mabry, E., et al. (2017). Medicinal properties of $\alpha$-santalol, a naturally occurring constituent of sandalwood oil: review. Nat. Prod. Res. doi: 10.1080/14786419.2017.1399387 [Epub ahead of print].

Browning, J. C., Rock, J., Levenson, C., and Becker, E. M. (2017). “Safety, tolerability and efficacy of a novel regimen containing $0.1 \%$ colloidal oatmeal and East Indian sandalwood oil (EISO) for the treatment of mild, moderate and severe pediatric eczema (atopic dermatitis) - results of a single-center, open-label study," in Poster at the Orlando Derm and Clinical Aesthetic Conference, Doral, FL.

Burdock, G. A., and Carabin, I. G. (2008). Safety assessment of sandalwood oil (Santalum album L.). Food Chem. Toxicol. 46, 421-432. doi: 10.1016/j.fct.2007. 09.092

Carroll, C. L., Balkrishnan, R., Feldman, S. R., Fleischer, A. B. Jr., and Manuel, J. C. (2005). The burden of atopic dermatitis: impact on the patient, family, and society. Pediatr. Dermatol. 22, 192-199. doi: 10.1111/j.1525-1470.2005. 22303.x

Chiricozzi, A., Suárez-Fariñas, M., Fuentes-Duculan, J., Cueto, I., Li, K., Tian, S., et al. (2016). Increased expression of interleukin-17 pathway genes in nonlesional skin of moderate-to-severe psoriasis vulgaris. Br. J. Dermatol. 174, 136-145. doi: 10.1111/bjd.14034

Cox, M. E., Deeble, P. D., Lakhani, S., and Parsons, S. J. (1999). Acquisition of neuroendocrine characteristics by prostate tumor cells is reversible: implications for prostate cancer progression. Cancer Res. 59, 3821-3830.

Czarnowicki, T., Krueger, J. G., and Guttman-Yassky, E. (2014). Skin barrier and immune dysregulation in atopic dermatitis: an evolving story with important clinical implications. J. Allergy Clin. Immunol. Pract. 2, 371-379; quiz 380-381. doi: 10.1016/j.jaip.2014.03.006

Dousa, T. P. (1999). Cyclic-3', $5^{\prime}$-nucleotide phosphodiesterase isozymes in cell biology and pathophysiology of the kidney. Kidney Int. 55, 29-62. doi: 10.1046/ j.1523-1755.1999.00233.x

Dwivedi, C., Maydew, E. R., Hora, J. J., Ramaeker, D. M., and Guan, X. (2005). Chemopreventive effects of various concentrations of $\alpha$-santalol 
on skin cancer development in CD-1 mice. Eur. J. Cancer Prev. 14, $473-476$.

Dwivedi, C., Valluri, H. B., Guan, X., and Agarwal, R. (2006). Chemopreventive effects of $\alpha$-santalol on ultraviolet B radiation-induced skin tumor development in SKH-1 hairless mice. Carcinogenesis 27, 1917-1922. doi: 10.1093/carcin/ bgl058

Elwood, C. N., Lange, D., Nadeau, R., Seney, S., Summers, K., Chew, B. H., et al. (2010). Novel in vitro model for studying ureteric stent-induced cell injury. BJU Int. 105, 1318-1323. doi: 10.1111/j.1464-410X.2009.09001.x

Gittler, J. K., Shemer, A., Suárez-Fariñas, M., Fuentes-Duculan, J., Gulewicz, K. J., Wang, C. Q., et al. (2012). Progressive activation of $\mathrm{T}(\mathrm{H}) 2 / \mathrm{T}(\mathrm{H}) 22$ cytokines and selective epidermal proteins characterizes acute and chronic atopic dermatitis. J. Allergy Clin. Immunol. 130, 1344-1354. doi: 10.1016/j.jaci. 2012.07.012

Gobejishvili, L., Barve, S., Joshi-Barve, S., and McClain, C. (2008). Enhanced PDE4B expression augments LPS-inducible TNF expression in ethanol-primed monocytes: relevance to alcoholic liver disease. Am. J. Physiol. Gastrointest. Liver Physiol. 295, G718-G724. doi: 10.1152/ajpgi.90232.2008

Grossman, R. M., Krueger, J., Yourish, D., Granelli-Piperno, A., Murphy, D. P., May, L. T., et al. (1989). Interleukin 6 is expressed in high levels in psoriatic skin and stimulates proliferation of cultured human keratinocytes. Proc. Natl. Acad. Sci. U.S.A. 86, 6367-6371. doi: 10.1073/pnas.86.16.6367

Guo, J., Lin, P., Zhao, X., Zhang, J., Wei, X., Wang, Q., et al. (2014). Etazolate abrogates the lipopolysaccharide (LPS)-induced downregulation of the cAMP/pCREB/BDNF signaling, neuroinflammatory response and depressive-like behavior in mice. Neuroscience 263, 1-14. doi: 10.1016/j. neuroscience.2014.01.008

Guttman-Yassky, E., Nograles, K. E., and Krueger, J. G. (2011). Contrasting pathogenesis of atopic dermatitis and psoriasis-part I: clinical and pathologic concepts. J. Allergy Clin. Immunol. 127, 1110-1118. doi: 10.1016/j.jaci.2011. 01.053

Hanifin, J. M., Thurston, M., Omoto, M., Cherill, R., Tofte, S. J., Graeber, M., et al. (2001). The eczema area and severity index (EASI): assessment of reliability in atopic dermatitis. EASI Evaluator Group. Exp. Dermatol. 10, 11-18. doi: 10.1034/j.1600-0625.2001.100102.x

Houslay, M. D., Schafer, P., and Zhang, K. Y. (2005). Keynote review: phosphodiesterase-4 as a therapeutic target. Drug Discov. Today 10, 1503-1519. doi: 10.1016/S1359-6446(05)03622-6

Hsu, L., and Armstrong, A. W. (2014). JAK inhibitors: treatment efficacy and safety profile in patients with psoriasis. J. Immunol. Res. 2014:283617. doi: 10.1155/ 2014/283617

Jin, S. L., and Conti, M. (2002). Induction of the cyclic nucleotide phosphodiesterase PDE4B is essential for LPS-activated TNF- $\alpha$ responses. Proc. Natl. Acad. Sci. U.S.A. 99, 7628-7633. doi: 10.1073/pnas.122041599

Koga, S., Morris, S., Ogawa, S., Liao, H., Bilezikian, J. P., Chen, G., et al. (1995). TNF modulates endothelial properties by decreasing cAMP. Am. J. Physiol. 268, C1104-C1113. doi: 10.1152/ajpcell.1995.268.5.C1104

Kotera, J., Yanaka, N., Fujishige, K., Imai, Y., Akatsuka, H., Ishizuka, T., et al. (1997). Expression of rat cGMP-binding cGMP-specific phosphodiesterase mRNA in Purkinje cell layers during postnatal neuronal development. Eur. J. Biochem. 249, 434-442. doi: 10.1111/j.1432-1033.1997.t01-1-00434.x

Leshem, Y. A., Hajar, T., Hanifin, J. M., and Simpson, E. L. (2015). What the Eczema area and severity index score tells us about the severity of atopic dermatitis: an interpretability study. Br. J. Dermatol. 172, 1353-1357. doi: 10.1111/bjd. 13662

Lowes, M. A., Suarez-Farinas, M., and Krueger, J. G. (2014). Immunology of psoriasis. Annu. Rev. Immunol. 32, 227-255. doi: 10.1146/annurev-immunol032713-120225

Lugnier, C., Keravis, T., Le Bec, A., Pauvert, O., Proteau, S., and Rousseau, E. (1999). Characterization of cyclic nucleotide phosphodiesterase isoforms associated to isolated cardiac nuclei. Biochim. Biophys. Acta 1472, 431-446. doi: 10.1016/ S0304-4165(99)00145-2

MacKenzie, S. J., and Houslay, M. D. (2000). Action of rolipram on specific PDE4 CAMP phosphodiesterase isoforms and on the phosphorylation of cAMPresponse-element-binding protein (CREB) and p38 mitogen-activated protein (MAP) kinase in U937 monocytic cells. Biochem. J. 347, 571-578. doi: 10.1042/ 0264-6021:3470571
Mancini, A. J., Kaulback, K., and Chamlin, S. L. (2008). The socioeconomic impact of atopic dermatitis in the United States: a systematic review. Pediatr. Dermatol. 25, 1-6. doi: 10.1111/j.1525-1470.2007.00572.x

Martinez, A., and Gil, C. (2014). cAMP-specific phosphodiesterase inhibitors: promising drugs for inflammatory and neurological diseases. Expert Opin. Ther. Pat. 24, 1311-1321. doi: 10.1517/13543776.2014.968127

Michalski, J. M., Golden, G., Ikari, J., and Rennard, S. I. (2012). PDE4: a novel target in the treatment of chronic obstructive pulmonary disease. Clin. Pharmacol. Ther. 91, 134-142. doi: 10.1038/clpt.2011.266

Miotla, J. M., Teixeira, M. M., and Hellewell, P. G. (1998). Suppression of acute lung injury in mice by an inhibitor of phosphodiesterase type 4. Am. J. Respir. Cell Mol. Biol. 18, 411-420. doi: 10.1165/ajrcmb.18.3.2913

Morizane, S., and Gallo, R. L. (2012). Antimicrobial peptides in the pathogenesis of psoriasis. J. Dermatol. 39, 225-230. doi: 10.1111/j.1346-8138.2011.01483.x

Moy, R. L., Levenson, C., So, J. J., and Rock, J. A. (2012). Single-center, openlabel study of a proprietary topical $0.5 \%$ salicylic acid-based treatment regimen containing sandalwood oil in adolescents and adults with mild to moderate acne. J. Drugs Dermatol. 11, 1403-1408.

Newman, D. J., and Cragg, G. M. (2012). Natural products as sources of new drugs over the 30 years from 1981 to 2010. J. Nat. Prod. 75, 311-335. doi: $10.1021 / \mathrm{np} 200906 \mathrm{~s}$

Noda, S., Krueger, J. G., and Guttman-Yassky, E. (2015). The translational revolution and use of biologics in patients with inflammatory skin diseases. J. Allergy Clin. Immunol. 135, 324-336. doi: 10.1016/j.jaci.2014.11.015

Nograles, K. E., Zaba, L. C., Guttman-Yassky, E., Fuentes-Duculan, J., Suárez-Fariñas, M., Cardinale, I., et al. (2008). Th17 cytokines interleukin (IL)-17 and IL-22 modulate distinct inflammatory and keratinocyte-response pathways. Br. J. Dermatol. 159, 1092-1102. doi: 10.1111/j.1365-2133.2008. 08769.x

Oger, S., Mehats, C., Dallot, E., Cabrol, D., and Leroy, M. J. (2005). Evidence for a role of phosphodiesterase 4 in lipopolysaccharide-stimulated prostaglandin E2 production and matrix metalloproteinase- 9 activity in human amniochorionic membranes. J. Immunol. 174, 8082-8089. doi: 10.4049/jimmunol.174.12.8082

Oldenburger, A., Roscioni, S. S., Jansen, E., Menzen, M. H., Halayko, A. J., Timens, W., et al. (2012). Anti-inflammatory role of the cAMP effectors Epac and PKA: implications in chronic obstructive pulmonary disease. PLoS One 7:e31574. doi: 10.1371/journal.pone.0031574

Oliva, A. A. Jr., Kang, Y., Furones, C., Alonso, O. F., Bruno, O., Dietrich, W. D., et al. (2012). Phosphodiesterase isoform-specific expression induced by traumatic brain injury. J. Neurochem. 123, 1019-1029. doi: 10.1111/jnc.12049

Ouagued, M., Martin-Chouly, C. A., Brinchault, G., Leportier-Comoy, C., Depincé, A., Bertrand, C., et al. (2005). The novel phosphodiesterase 4 inhibitor, CI-1044, inhibits LPS-induced TNF- $\alpha$ production in whole blood from COPD patients. Pulm. Pharmacol. Ther. 18, 49-54. doi: 10.1016/j.pupt.2004.09.031

Paller, A. S., Tom, W. L., Lebwohl, M. G., Blumenthal, R. L., Boguniewicz, M., Call, R. S., et al. (2016). Efficacy and safety of crisaborole ointment, a novel, nonsteroidal phosphodiesterase 4 (PDE4) inhibitor for the topical treatment of atopic dermatitis (AD) in children and adults. J. Am. Acad. Dermatol. 75, 494.e6-503.e6. doi: 10.1016/j.jaad.2016.05.046

Parisi, R., Symmons, D. P., Griffiths, C. E., and Ashcroft, D. M. (2013). Global epidemiology of psoriasis: a systematic review of incidence and prevalence. J. Invest. Dermatol. 133, 377-385. doi: 10.1038/jid.2012.339

Parry, G. C., and Mackman, N. (1997). Role of cyclic AMP response elementbinding protein in cyclic AMP inhibition of NF- $\kappa$ B-mediated transcription. J. Immunol. 159, 5450-5456.

Pullamsetti, S. S., Banat, G. A., Schmall, A., Szibor, M., Pomagruk, D., Hänze, J., et al. (2013). Phosphodiesterase-4 promotes proliferation and angiogenesis of lung cancer by crosstalk with HIF. Oncogene 32, 1121-1134. doi: 10.1038/onc. 2012.136

Santha, S., Bommareddy, A., Rule, B., Guillermo, R., Kaushik, R. S., Young, A., et al. (2013). Antineoplastic effects of $\alpha$-santalol on estrogen receptorpositive and estrogen receptor-negative breast cancer cells through cell cycle arrest at G2/M phase and induction of apoptosis. PLoS One 8:e56982. doi: 10.1371/journal.pone.0056982

Schafer, P. (2012). Apremilast mechanism of action and application to psoriasis and psoriatic arthritis. Biochem. Pharmacol. 83, 1583-1590. doi: 10.1016/j.bcp. 2012.01.001 
Schafer, P. H., Parton, A., Capone, L., Cedzik, D., Brady, H., Evans, J. F., et al. (2014). Apremilast is a selective PDE4 inhibitor with regulatory effects on innate immunity. Cell. Signal. 26, 2016-2029. doi: 10.1016/j.cellsig.2014.05.014

Schett, G., Sloan, V. S., Stevens, R. M., and Schafer, P. (2010). Apremilast: a novel PDE4 inhibitor in the treatment of autoimmune and inflammatory diseases. Ther. Adv. Musculoskelet. Dis. 2, 271-278. doi: 10.1177/1759720X10 381432

Seybold, J., Newton, R., Wright, L., Finney, P. A., Suttorp, N., Barnes, P. J., et al. (1998). Induction of phosphodiesterases 3B, 4A4, 4D1, 4D2, and 4D3 in Jurkat T-cells and in human peripheral blood T-lymphocytes by 8-bromocAMP and $G_{s}$-coupled receptor agonists. Potential role in $\beta_{2}$-adrenoreceptor desensitization. J. Biol. Chem. 273, 20575-20588. doi: 10.1074/jbc.273.32. 20575

Sharma, M., Levenson, C., Bell, R. H., Anderson, S. A., Hudson, J. B., Collins, C. C., et al. (2014). Suppression of lipopolysaccharide-stimulated cytokine/chemokine production in skin cells by sandalwood oils, and purified $\alpha$-santalol, and beta-santalol. Phytother. Res. 28, 925-932. doi: 10.1002/ptr.5080

Sharma, M., Levenson, C., Clements, I., Castella, P., Gebauer, K., and Cox, M. E. (2017). East Indian sandalwood oil (EISO) alleviates inflammatory and proliferative pathologies of psoriasis. Front. Pharmacol. 8:125. doi: 10.3389/ fphar.2017.00125

Sigurdsson, V., Vries, I. J., Toonstra, J., Bihari, I. C., Thepen, T., BruijnzeelKoomen, C. A., et al. (2000). Expression of VCAM-1, ICAM-1, E-selectin, and P-selectin on endothelium in situ in patients with erythroderma, mycosis fungoides and atopic dermatitis. J. Cutan. Pathol. 27, 436-440. doi: 10.1034/j. 1600-0560.2000.027009436.x

Smith, S. J., Cieslinski, L. B., Newton, R., donnelly, L. E., Fenwick, P. S., Nicholson, A. G., et al. (2004). Discovery of BRL 50481 [3-(N,N-dimethylsulfonamido)4-methyl-nitrobenzene], a selective inhibitor of phosphodiesterase 7 : in vitro studies in human monocytes, lung macrophages, and CD8+ T-lymphocytes. Mol. Pharmacol. 66, 1679-1689. doi: 10.1124/mol.104.002246

Takahashi, N., Tetsuka, T., Uranishi, H., and Okamoto, T. (2002). Inhibition of the NF-кB transcriptional activity by protein kinase A. Eur. J. Biochem. 269, 4559-4565. doi: 10.1046/j.1432-1033.2002.03157.x

Tang, S. C., Liao, P. Y., Hung, S. J., Ge, J. S., Chen, S. M., Lai, J. C., et al. (2017). Topical application of glycolic acid suppresses the UVB induced IL-6, IL-8, MCP-1 and COX-2 inflammation by modulating NF- $\kappa$ B signaling pathway in keratinocytes and mice skin. J. Dermatol. Sci. 86, 238-248. doi: 10.1016/j. jdermsci.2017.03.004
Toward, T. J., and Broadley, K. J. (2001). Chronic lipopolysaccharide exposure on airway function, cell infiltration, and nitric oxide generation in conscious guinea pigs: effect of rolipram and dexamethasone. J. Pharmacol. Exp. Ther. 298, 298-306.

van Staveren, W. C., and Markerink-van Ittersum, M. (2005). Localization of cyclic guanosine $3^{\prime}, 5^{\prime}$-monophosphate-hydrolyzing phosphodiesterase type 9 in rat brain by nonradioactive in situ hydridization. Methods Mol. Biol. 307, 75-84. doi: 10.1385/1-59259-839-0:075

Weidinger, S., and Novak, N. (2016). Atopic dermatitis. Lancet 387, 1109-1122. doi: 10.1016/S0140-6736(15)00149-X

Wittmann, M., and Helliwell, P. S. (2013). Phosphodiesterase 4 inhibition in the treatment of psoriasis, psoriatic arthritis and other chronic inflammatory diseases. Dermatol. Ther. 3, 1-15. doi: 10.1007/s13555-013-0023-0

Wright, L. C., Seybold, J., Robichaud, A., Adcock, I. M., and Barnes, P. J. (1998). Phosphodiesterase expression in human epithelial cells. Am. J. Physiol. 275, L694-L700. doi: 10.1152/ajplung.1998.275.4.L694

Yang, I. A., Relan, V., Wright, C. M., Davidson, M. R., Sriram, K. B., Savarimuthu Francis, S. M., et al. (2011). Common pathogenic mechanisms and pathways in the development of COPD and lung cancer. Expert Opin. Ther. Targets 15, 439-456. doi: 10.1517/14728222.2011.555400

Zambon, A. C., Zhang, L., Minovitsky, S., Kanter, J. R., Prabhakar, S., Salomonis, N., et al. (2005). Gene expression patterns define key transcriptional events in cell-cycle regulation by cAMP and protein kinase A. Proc. Natl. Acad. Sci. U.S.A. 102, 8561-8566. doi: 10.1073/pnas.0503363102

Conflict of Interest Statement: CL, IC, and PC are employees of Santalis Pharmaceuticals, Inc.

The other authors declare that the research was conducted in the absence of any commercial and financial relationships that could be construed as a potential conflict of interest.

Copyright (c) 2018 Sharma, Levenson, Browning, Becker, Clements, Castella and Cox. This is an open-access article distributed under the terms of the Creative Commons Attribution License (CC BY). The use, distribution or reproduction in other forums is permitted, provided the original author(s) and the copyright owner are credited and that the original publication in this journal is cited, in accordance with accepted academic practice. No use, distribution or reproduction is permitted which does not comply with these terms. 